\title{
Examining the Moderator Role of Gender in the Association Between Self-Reflection and Spirituality
}

\author{
Hennira Rohyatin ${ }^{1}$ \\ University of Muhammadiyah Malang \\ Latipun Latipun $^{3}$
University of Muhammadiyah Malang
}

\author{
Merlyn Ika R.P. ${ }^{2}$ \\ University of Muhammadiyah Malang
}

Iswinarti $^{4}$
University of Muhammadiyah Malang

1 Master of Psychology Student, University of Muhammadiyah Malang. E-mail: heynirarohyatin@gmail.com
${ }^{2}$ Master of Psychology Student, University of Muhammadiyah Malang. E-mail: Merlynika@gmail.com
${ }^{3}$ Professor at the Psychology Department, University of Muhammadiyah Malang. E-mail: lativ_un1@yahoo.com
${ }^{4}$ Professor at the Psychology Department, University of Muhammadiyah Malang. E-mail: iswinarti@umm.ac.id

Corresponding author: Hennira Rohyatin

E-mail:

heynirarohyatin@gmail.com

eISSN: $2458-9675$

Received: 08.05.2020

Revision: 11.10 .2020

Accepted: 14.10 .2020

(C) Copyright 2020

by Author(s)

\begin{abstract}
Spirituality and religiosity are increasingly becoming a necessity for each individual in supporting the quality and well-being of life. Student involvement in self-reflection affects their spirituality / religiosity. This study aims to determine the relationship between self-reflection and spirituality/religiousness $(\mathrm{S} / \mathrm{R})$, which is moderated by gender. This research uses a quantitative approach with a correlational design. The study sample consisted of 124 students with a mean age of 19.4 years. The total sample was obtained from 98 women and 26 men. Sample selected from students majoring in Elementary School Teachers (PGSD) in various semesters with a purposive sampling method. Measuring instruments used are the Ironson-Wood Spirituality/religiousness Index (IWSRI) and The Self-Reflection and Insight Scale (SRIS). Data analysis using Process Macros. The results showed that there was a significant effect of self-reflection on spirituality/religiousness $(B=0.669 ; \mathrm{p}=0.000$, ) and gender could not moderate the effect of self-reflection on spirituality/religiousness on students of Elementary School Teachers (PGSD) $(B=-0.317 ; \mathrm{p}=0.369)$. Based on research conducted, it can be concluded that self-reflection significantly influences spirituality/religiousness, and gender is not able to strengthen or weaken the effect of self-reflection on spirituality/ religiousness; thus, gender cannot become a moderator between self-reflection and spirituality/religiousness.

Keywords:

Self-Reflection, Gender, Spirituality, Religiosity, Moderator Role
\end{abstract}

Citation: Rohyatin, H., Ika R.P., M., Latipun, L., \& Iswinarti. (2020). Examining the moderator role of gender in the association between self-reflection and spirituality. Spiritual Psychology and Counseling, 5, 301-312. https://dx.doi.org/10.37898/spc.2020.5.3.109 
Humans are created as beings who have an inner instinct that requires transcendence in life. The ability of humans to become transcendent beings is by increasing spirituality in themselves (Rassoulian, Seidman, \& Löffler-Stastka, 2016). Many human beings have reached or fulfilled biological needs to the fulfillment of selfactualization needs but often feel the emptiness in their soul. Spirituality significantly influences the quality of human life (Counted, Possamai, \& Meade, 2018). Spirituality has become a basic need for humans without exception. Spirituality is one of the integral parts of religiosity. Ironson, Solomon, \& Med (2002) combine spirituality with religiosity, even though it is different. In practice, both spirituality and religion are going together, like a current program in education, namely increasing morality through increased spirituality by increasing the religiosity of teachers and students.

Teachers who devote themselves to educating humans need welfare and mental health. When teachers as educators already have good mental health and are aware of it, it can also affect the mental health of their students. Spirituality/religiousness $(\mathrm{S} / \mathrm{R})$ of teachers in Elementary Schools proven to have a positive effect on their welfare and mental health as teachers (Park, 2016). The mental health of elementary school teachers ultimately affects the mental health of the students they educate (Johal \& Pooja, 2016). Meanwhile, various complex problems in education, such as the unequal distribution of teachers, the quality and quantity of teachers, then the learning difficulties experienced by students become stressors of the teachers and, if left unchecked, can be a trigger for mental illness. So improvements in spirituality can help to reduce the impact of these problems.

Spirituality and religiosity correlate the internal dialogue within individuals (Zarzycka \& Puchalska, 2019), which means that individuals do self-reflection aimed to confirm what they believe in and to give instructions to themselves in their behavior. According to Malatji \& Wadesango (2017), reflection is an active process to witness their own experience to take a closer look to draw attention briefly, but often for men to explore in more depth. It can be done in the middle of an activity or make it daily activities. The key to reflection is learning how to take the perspective of the action and experience themselves (Helyer, 2015). In other words, self-reflection function to examine the experience of self and not just simply undergo such experiences without meaning so that life becomes meaningful and mental health increases.

Spirituality and religiosity related to what is valued by individuals in doing something. The results of the study showed a relationship between mental health and spirituality/religiousness (Ironson, Cleirigh, \& Costa, 2009). Besides, self-reflection is explicitly associated with spirituality and mental health (Tan, 2016). To improve spirituality/religiousness, especially in Elementary School Teachers (PGSD) students who will become educators, one of the efforts that need to be done is to determine the effect of self-reflection on spirituality/religiousness. Nevertheless, not much research 
showed an interest in the influence of self-reflection and spirituality/religiousness. Therefore, this study seeks to examine the relationship between self-reflection and spirituality/religiousness moderated by gender.

\section{Spirituality and Religiosity}

Distinguishing between religiosity and spiritual quality is not easy for monoculture in a cross-cultural country. Thoughts for centuries have not provided a standard depiction of the two concepts (Koenig, 2012). One difficulty is that the two concepts are interrelated and have general characteristics, both of which can involve personal transformation and the best search for truth (Ironson, Solomon, \& Med, 2002). Religious people often define themselves as spiritual beings, so spirituality often includes religiosity, yet, spirituality is often described in broader terms.

Religion generally associates with certain fundamental principles organized in belief systems of different religious practices. Spirituality is more challenging to define, especially cross-culturally, because the character of the stick is not readily agreed, and that can mean something different for different individuals in different places (Koenig, 2012). Also, spirituality conveys the idea of personal search related to things that are sacred and transcendent (Rassoulian, Seidman, \& Löffler-Stastka, 2016), while the level of religiosity worldwide often measured straightforwardly (Lucchetti, Lucchetti, \& Vallada, 2013). For example, regarding the frequency of activities, such as ritual practices and presence in places of worship. Religious activities are also not always considered to occur. They are bound to individual official institutions when discussing spirituality because spirituality has taken on a more personal part and can occur inside or outside the formal institution of religion.

In many ways, religiosity is more accessible to measure than spirituality. The personal search in spirituality often includes indirect indicators, such as deep thoughts about self and other transcendental aspects (Zimmer, Jagger, Chiu, Ofstedal, Rajo, \& Saito, 2016). This type of measurement shows the extent of spirituality. In some contexts, many people say that they reflect the meaning of life, meditate, or participate in ritual activities and do not say that they are in a specific religion. However, spirituality and religiosity are often considered together, especially when researching the steps of individual search relating to the meaning of life. Another ambiguity in distinguishing religiosity from spirituality is that both can involve contemplative activity. Religious activities can include prayer and preaching. The study of spirituality and health has expanded to consider the impact of non-meditation (Davidson et al., 2003). Hence, prayer can be considered as an internal conversation with the power of God. Then, there is meditation, which is considered as an effort of deep concentration by doing a more specific focus, such as on the breath, or an effort to have very conscious feelings, related to particular thoughts and experiences of a person. Also, like religion and spirituality, 
there is a close relationship between prayer and meditation, so that both are thought to cause physical and mental relaxation (Ivanovski \& Malhi, 2007). Therefore, some researchers like Ironson, Solomon, \& Med (2002) combine spirituality with religiosity.

\section{Self-reflection and Spirituality/Religiousness}

Reflection is an active process in witnessing the subjective experience alone with closer to direct others' attention briefly but is also often used for men to explore themselves more deeply (Malatji \& Wadesango, 2017). Reflection can be done amid a particular activity and is made as an individual activity in daily life. The key to reflection is learning how to take perspective on one's actions and experiences. In other words, self-reflection is used to check each experience that must not only live it. The skill of reflection needed to analyze and prioritize having second thoughts, deepening self -based knowledge resources, and developing a plan into action. According to Bubnys ( 2019), reflection is not about one event at a time, but experiences that repeatedly occur when the teacher wants me to begin to construct meaning for them. Thus, the reflection process needs to be carried out continuously to obtain meaning in each experience of life. A reflective person can take responsibility (Lew \& Schmidt, 2011). Therefore self-reflection is needed in thinking, feeling, and living various thoughts and actions in daily life, especially in the transcendent dimension, to create a meaningful atmosphere in every life experience.

\section{Self-reflection, Gender as a Moderator and Spirituality/Religiousness Variable}

Every individual who performs self-reflection or self-reflection will have a higher spirituality and religiosity compared to those who do not perform self-reflection. When spirituality increases, mental health, and well-being will increase (Sood, Bakhshi, \& Gupta, 2012). Spirituality/religiousness refers to beliefs and deeds based on beliefs such as the transcendent dimension of life.

Spirituality is something sacred in life due to the values of transcendence as well as its relationship with the Creator (Peterson \& Seligman, 2004). Besides, gender, age, and culture can influence one's spirituality (Ironson, Cleirigh, \& Costa, 2009). Therefore, this study wants to examine the relationship of self-reflection to spirituality, which is moderated by gender.

Figure 1:

Thinking Framework

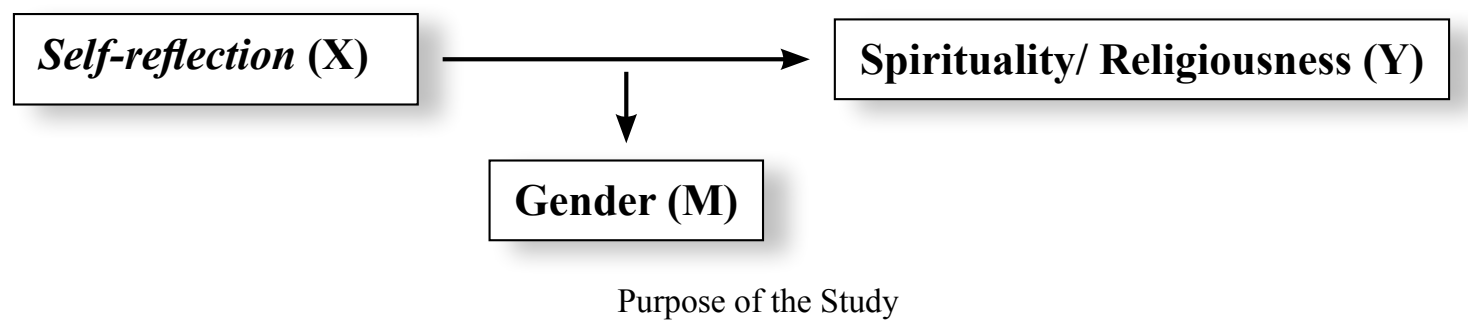


The purpose of this study was to examine the positive relationship between selfreflection and spirituality/religiousness, while gender moderates the relationship between self-reflection and spirituality/religiousness among students at the University of Muhammadiyah Malang.

\section{Method}

\section{Research Design}

This research is the quantitative approach, namely correlational design that illustrates the research problem through a description of trends or the need for an explanation of the relationship between variables. Quantitative is a systematic approach that makes a statement of research objectives clearly, makes specific research questions and hypotheses, measurable, and observable (Creswell, 2012). In this study, a quantitative approach is used to determine the relationship between selfreflection and spirituality/religiousness, which is moderated by gender variables.

\section{Study Group}

The research sample was taken using purposive sampling method. Several sample criteria have been set, such as the sample is students of the University of Muhammadiyah Malang majoring in Elementary School Teachers (PGSD) who are in semester I, III, V, and VII aged 18 years to 21 years amounted to 124 students. The study was conducted in the odd semester; the research subjects from Semester I to Semester VII were selected randomly. In detail, the participants include 27 students aged 18 years old, 39 students aged 19 years old, 37 students aged 20 years old, and 19 students aged 21 years old, while the sexes include 26 male students and 98 female students.

Table 1.

Characteristics of the Subjects $(N=124)$

\begin{tabular}{lll}
\hline Characteristics & $\mathrm{N}$ & $\%$ \\
\hline Gender & & 20.97 \\
\hline Male & 26 & 79.03 \\
Girl & 98 & \\
Age & & 21.77 \\
18 & 27 & 31.45 \\
19 & 39 & 29.84 \\
20 & 37 & 16.93 \\
21 & 21 & \\
Semester & & 45.88 \\
I & 37 & 55.80 \\
III & 37 & 39.68 \\
V & 45 & 12.40 \\
VII & 32 & 10 \\
\hline
\end{tabular}




\section{Data Collection Tools}

The instruments used in this study were the Ironson-Wood Spirituality / Religiousness Index (IWSRI) to measure spirituality / religiosity and the SelfReflection and Insight Scale (SRIS) to measure self-reflection. In addition, the Sociodemographic Information Form was used to collect information about the sociodemographic characteristics of the participants in the study group.

\section{Ironson-Wood Spirituality / Religiousness Index (IWSRI)}

The Ironson-Wood Spirituality / Religiousness Index (IWSRI) measures spirituality/ religiousness (S/R) in students (IWSRI) compiled and developed by Ironson, Solomon, $\&$ Med (2002). The IWSRI scale is a Likert scale type with five answer choices, namely strongly disagree (1) to strongly agree (5). The IWSRI scale consists of 25 items and is divided into four factors, namely peace, faith in God, religious behavior, and compassionate views on others. The first factor includes a sense of peace, which has three indicators, namely comfort, strength, and meaning (four items); feel right connections, not lonely (three-item); and existential/final life (two items). The second factor is about faith in God, which has two indicators, namely a view of God (two items) and somatic recovery/illness (four items). The third factor is religious behavior, which has five items. Then, the fourth factor is a compassionate view of others, which also has five items. High scores on the IWSRI scale indicate high spirituality/religiousness in students. Example statement: "My belief gives me peace." In the research trial, the IWSRI scale has a Cronbach internal consistency value of 0.936 .

\section{The Self-Reflection and Insight Scale (SRIS).}

The Self-Reflection and Insight Scale (SRIS) has three factors: the need for reflection, engagement in reflection, and insight. Self-reflection is measured by The Self-Reflection and Insight Scale (SRIS) developed by Grant et al. (2006). It is a Likert type scale with five choices of strongly disagree (1) to strongly agree (5). The SRIS scale consists of 20 items; six items measure individual involvement in self-reflection, six items measure individual needs for self-reflection, and eight items measure understanding. A high score indicates a high level of self-reflection and self- understanding. Example of the statement: "It's important for me to evaluate the things I'm doing." In the research trial, the SRIS scale has a Cronbach's internal consistency value of 0.643 .

\section{Sociodemographic Information Form}

The sociodemographic information forms used by participants in this study included age, gender, year of birth, faculty, department, semester, origins and religious beliefs. 


\section{Data Collection Process}

The data collection process in this study used questionnaires from The Ironson-Wood Spirituality/Religiousness Index (IWSRI) measures spirituality/religiousness (S/R) and The Self-Reflection and Insight Scale (SRIS) measures Self-Reflection. Data was collected from 9 December 2019 to 12 December 2019. Data collection was carried out in class during class hours by asking permission from the lecturer who was filling in the class. The data collection process was carried out for four days in various semesters. Each semester is represented by a class whose students are still learning in the classroom with the lecturer. Data collection on sample semester 1 on Monday, 9 December 2019. Data collection on sample semester 3 on Tuesday, 10 December 2019. Data collection on sample semester 5 on Wednesday, 11 December 2019. Data collection on sample semester 7 on the day Thursday, 12 December 2019. Each semester is represented by one class. Completing the questionnaire takes 20-30 minutes.

\section{Data Analysis}

The data analysis is using SPSS 21 to test the relationship between independent variables and dependent variables with regression analysis. In contrast, process macros are used to test the function of moderator variables that function to strengthen or weaken the relationship between independent and dependent variables (Hayes, 2018).

\section{Results}

Based on the results of data analysis, the self-reflection variable obtained SD = 7.5363 with $\mathrm{M}=68.871$ which means that the research subjects have an average level of self-reflection which is high and on the variable spirituality/religiousness obtained $\mathrm{SD}=14.8517$ and $\mathrm{M}=104.113$ which means that the subjects in this study have a high average of spirituality/religiousness.

Table 2.

Description of Research Variables

\begin{tabular}{lcc}
\hline Variable & SD & M \\
\hline Self-reflection & 7,5363 & 68,871 \\
& 14.8517 & 104,113 \\
\hline
\end{tabular}

Note: $\mathrm{SD}=$ Standard Deviation; $\mathrm{M}=$ Mean or Average

In the gender variable, female students obtained $\mathrm{SD}=0,62004$ with $\mathrm{M}=4.1359$ while male students obtained $\mathrm{SD}=0,47893$ with $\mathrm{M}=4.2723$. It indicates that spirituality/religiousness in men and women shows almost the same results. 
Table 3.

Mean values and standard deviations of spirituality/religiousness by sex $(N=124)$.

\begin{tabular}{lcc}
\hline Gender Variable & SD & M \\
\hline Girl & 0,62004 & 4,1359 \\
Male & 0,47893 & 4,2723 \\
\hline
\end{tabular}

Note: $\mathrm{SD}=$ Standard Deviation; $\mathrm{M}=$ Mean or Average

The results of the data analysis test showed that there was a positive and significant correlation between self-reflection and spirituality/religiousness, indicated by the value of $\mathrm{B}=0.669$ and $\mathrm{p}=0.000$, so it can be concluded that the first hypothesis was accepted namely the higher the student's self-reflection, the more spirituality/ religiousness increase. On the contrary, the lower the self-reflection of students, the lower their spirituality/religiousness.

Then, it can be seen that gender in students is negatively correlated and not significant in the relationship between self-reflection and spirituality/religiousness, indicated by the value of $\mathrm{B}=-0.317$ and $\mathrm{p}=0.369$.

Table 4.

Relationships Between Variables

\begin{tabular}{lcc}
\hline Relationship Between Variables & B & P. \\
\hline Self-reflection spirituality/religiousness & .669 & 0,000 \\
Self-reflection * Gender spirituality/religiousness & $-0,317$ & .369 \\
\hline
\end{tabular}

Figure 2.

Results of Moderation of $X Y$ and $M$

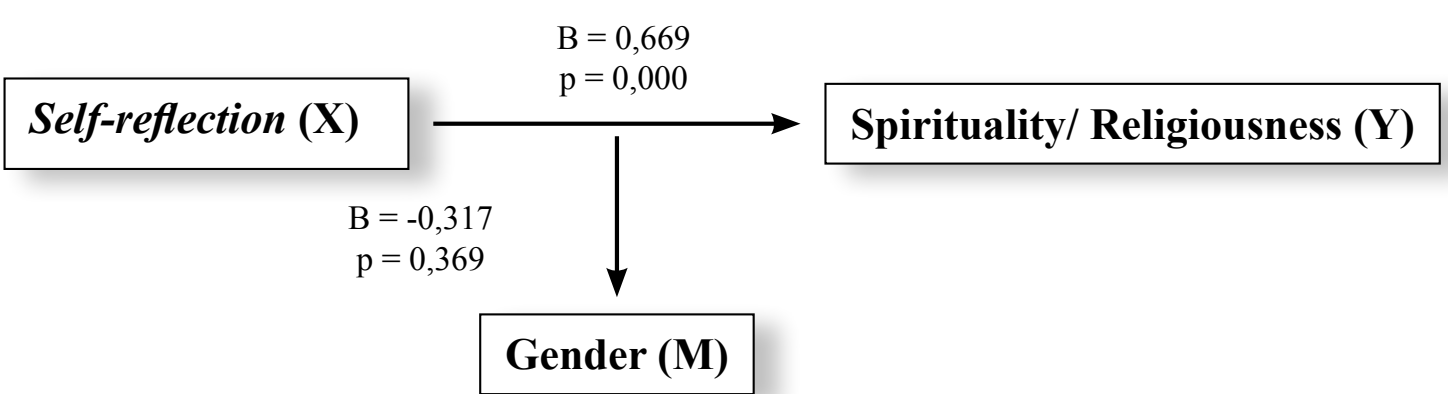

The analysis shows that gender cannot be the moderator of the relationship between self-reflection and spirituality/religiousness in students. Gender cannot strengthen the relationship between self-reflection and spirituality/religiousness in students, so the results of the interaction between self-reflection and gender variables in students will not be followed by an increase in spirituality/religiousness. 
Figure 3.

Moderation Graph

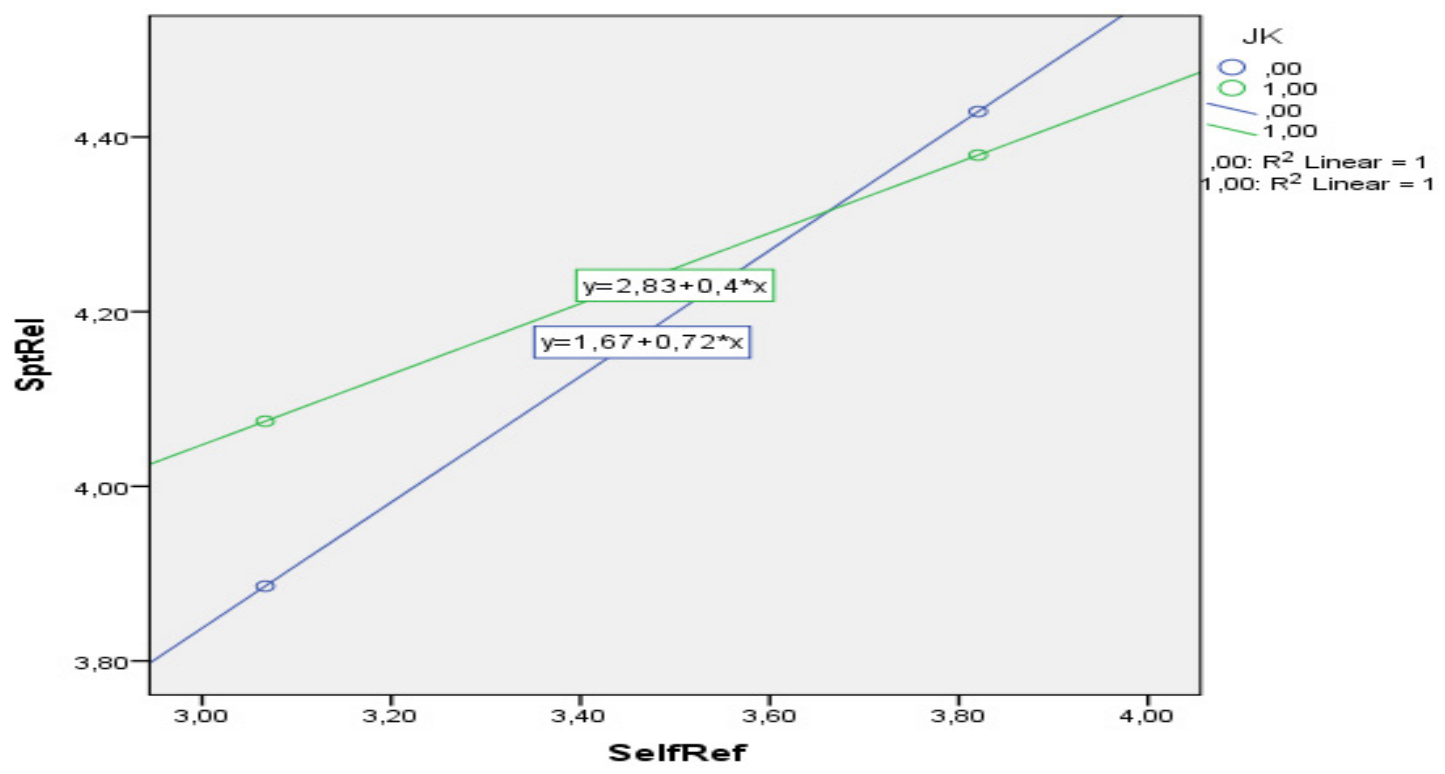

Figure 3 shows that positive relationships were found in both categories of male and female groups, that low self-reflection is indicated in the low spirituality/religiousness or high self-reflection is indicated by the high spirituality/religiousness. Both groups have a positive direction of relationship, so gender does not play a role as a moderator.

\section{Discussion}

Based on the results of the moderation analysis, it is known that self-reflection and spirituality/religiousness have a significant effect, indicated by the value of $p=0,000$, so that there is an effect of self-reflection on spirituality/religiousness. This is in line with Zarzycka \& Puchalska's research (2019), showing that individuals who carry out internal dialogue that is also related to self-reflection correlate with spirituality/religiousness.

Based on the analysis results, it is known that gender is not able to moderate selfreflection on spirituality/religiousness. This is in line with the research of Polisetty et al., (2017) that men and women do not affect spirituality/religiousness so that they cannot predict the relationship of self-reflection on spirituality/religiousness. Several studies have shown that differences in spirituality/religiousness in men and women are small (Barkan \& Greenwood, 2008).

Men and women mostly have the same strength of character in terms of creativity, curiosity, open-mindedness, learning, perspective, courage, perseverance, integrity, ability to live, love, kindness, social intelligence, citizenship, justice, leadership, compassion, humility, wisdom, ability to self-regulate, appreciate beauty or beauty, gratitude, have hope, ridiculing, and closeness to God. Most women have feelings of love, kindness, love attractiveness or beauty, and have a sense of gratitude higher 
than men. Gender is not able to moderate without involving age and other types of measurements in strengthening the character of a child - a child, adolescent, and adult (Froh, Yurkewicz, \& Kashdan, 2009).

Gender can moderate spirituality/religiousness if sex is seen from the personality owned and nationality. Both can be two sources that strengthen the spirituality/ religiousness accepted by individuals (Ironson, Cleirigh, \& Costa, 2009). Not only gender, but age also influences spirituality (Polisetty et al., 2017). Therefore, sex can be a moderator of the influence of self-reflection on spirituality/religiousness if put together with other variables.

Based on research conducted, it can be concluded that self-reflection significantly influences spirituality/religiousness, and gender is unable to strengthen or weaken the effect of self-reflection on spirituality/religiousness. This positive relationship was found in the group of men - men and women that the lack of self-reflection is indicated in the low spirituality/religiousness, or high self-reflection is indicated by the high spirituality/religiousness. Both groups have a positive direction to the relationship, so gender cannot act as a moderator.

In this study, gender is not able to strengthen or weaken the influence of selfreflection on spirituality/religiousness, while several research journals indicated that sex could become a moderate variable when going together with other variables. In determining the moderator variable, it is suggested for gender plus other variables such as age, social status, and culture.

For the next researchers, they are expected to define a more specific context in doing self-reflection so they could achieve more specific conclusions about the role of self-reflection in a specific context, such as in the context of teaching. Besides, it is to consider that spirituality/religiousness can occur conditionally; therefore, further researchers are expected to research at the right time. All individuals experience spirituality/religiousness at all education levels, so researchers can then examine other subjects at different levels of education and different majors. 


\section{References}

Barkan, S. E. \& Greenwood, S. F. (2008). Religious attendance and subjective well-being among older americans: Evidence from the general social survey. Journal Storage, 38(1), 3-17.

Bubnys, R. (2019). A journey of self-reflection in students' perception of practice and roles in the profession. Journal of Sustainability, 1-17. https://doi.org/10.3390/su11010194

Counted, V., Possamai, A., \& Meade, T. (2018). Relational spirituality and quality of life 2007 to 2017 : An integrative research review. Journal of Health and Quality of Life Outcomes, 1-18.

Creswell, John W. (2012). Planning, Conducting and Evaluating Quantitative and Qualitative Research. Boston: Pearson Education.

Davidson, R. J., Kabat-Zinn, J., Schumacher, J., Rosenkranz, M., Muller, D., Santorelli, S. F., ... Sheridan, J. F. (2003). Alterations in brain and immune function produced by mindfulness meditation. Psychosomatic Medicine, 65(4), 564-570. https://doi.org/10.1097/01. PSY.0000077505.67574.E3

Froh, J. J., Yurkewicz, C., \& Kashdan, T. B. (2009). Gratitude and subjective well-being in early adolescence: Examining gender differences. Journal of Adolescence, 32(3), 633-650. https:// doi.org/10.1016/j.adolescence.2008.06.006

Grant, A. M., Unit, C. P., Wales, S., Franklin, J., Langford, P., \& Psychology, C. (2006). The selfreflection and insight scale: A new measure of private self-consciousness. Social Behaviour \& Personality, 30(8), 821-836.

Hayes, F. A. (2018). No Title Introduction to Mediation, Moderation, and Conditional Process Analysis A Regression-Based Approach. New York: The Guilford Press.

Helye, R., (2015). Learning through reflection: thecritical role of reflection inwork-based learning (WBL) www.emeraldinsight.com/2205-2062.htm. Department of Academic Enterprise, Teesside University, Middlesbrough, UK

Ironson, G. H., Lo, C. E., Cleirigh, C. O., \& Costa, P. T. (2009). Five-factor model personality traits, spirituality/religiousness, and mental health among people living with HIV. Journal of Personality, 1411-1436. https://doi.org/10.1111/j.1467-6494.2009.00587.x

Ironson, G., Ph, D., Solomon, G. F., \& Med, A. B. (2002). The Ironson - Woods Spirituality / Religiousness Index Is Associated With Long Survival, Health Behaviors, Less Distress, and Low Cortisol in People With HIV / AIDS. The Society of Behavioral Medicine, 34-48.

Ivanovski, B., \& Malhi, G. S. (2007). The psychological and neurophysiological concomitants of mindfulness forms of meditation. Acta Neuropsychiatrica, 19(2), 76-91. https://doi.org/10.1111/ j.1601-5215.2007.00175.x

Johal, S. K., \& Pooja, M. (2016). Relationship between mental health and psychological well being of prospective female teachers. IOSR Journal of Research \& Method In Education, 6(1), 1-6. https://doi.org/10.9790/7388-06120106

Koenig, H. G. (2012). Religion, spirituality, and health : The Research and Clinical Implications. International Scholarly Research Network, 1-33. https://doi.org/10.5402/2012/278730

Lew, M. D. N., \& Schmidt, H. G. (2011). Self-reflection and academic performance : is there a relationship ?. Adv In Health Sciences Education, 529-545. https://doi.org/10.1007/s10459-011-9298-z

Malatji, K. S., \& Wadesango, N. (2017). Self-reflection as a Tool to Improve Teaching Practice : The Practice and the Timing of Self-reflection by Primary Schools Teachers in the Mankweng Circuit, Capricorn District. Journal of Social Sciences, 41(3), 375-383. https://doi.org/10.1080/ 09718923.2014.11893372 
Park, C. L. (2016). Religiousness/Spirituality and Health: A meaning systems perspective. Journal of Behavioral Medicine, 1-11. https://doi.org/10.1007/s10865-007-9111-x

Peterson, C., \& Seligman, M. E. P. (2004). Character Strengths and Virtues: A Handbook and Classification. New York: Oxford University Press.

Polisetty, A., Ph, D., \& Sheela, P. (2017). Factors Influencing Spirituality. IOSR Journal of Business \& Management, 19(9), 38-42. https://doi.org/10.9790/487X-1909043842

Rassoulian. A., Seidman, Löffler-Stastka, H. (2016). Transcendence, religion and spirituality in medicine Observational Study.

Seifi, S., Ramyani, M. B., Faramarzi, M., \& Sum, S. (2018). Personality traits are associated with spiritual intelligence in medical and dental students: a study in a medical sciences university in iran. Journal of Medicine Sciences, 38(4), 144-149. https://doi.org/10.4103/jmedsci.jmedsci

Sood, S., Bakhshi, A., \& Gupta, R. (2012). Relationship between personality traits, spiritual intelligence and well being in university students. Journal of Education \& Practice, 3(10), 55-60.

Tan, C. (2016). Reflection for Spiritual Development in Adolescents. International Handbook For Spirituality, The Netherlands: Springer. https://doi.org/10.1007/978-1-4020-9018-9

Zarzycka, B., \& Puchalska, M. M. (2019). Can Religious and Spiritual Struggle Enhance Well Being ? Exploring the Mediating Effects of Internal Dialogues. Journal of Religion and Health, 1-16. https://doi.org/10.1007/s10943-018-00755-w

Zimmer, Z.,Jangger, C., Chiu, C., Ofstedal, M., Rojo, F.(2016). Pupulation Health. journal homepage: www.elsevier.com/locate/ssmphUniversity of California, San Francisco, USA. 